\title{
AVALIAÇÃO DO ESTADO AMBIENTAL DAS UNIDADES DE PAISAGEM DE UMA BACIA HIDROGRÁFICA DO ESTADO BRASILEIRO DE MATO GROSSO
}

\author{
Miriam Raquel da Silva Miranda ${ }^{1}$ \\ Sandra Mara Alves da Silva Neves ${ }^{2}$ \\ Cleber Aparecido de Barros ${ }^{3}$
}

\begin{abstract}
Resumo: Objetivo deste trabalho é avaliar o estado ambiental das unidades de paisagem de uma bacia hidrográfica do estado brasileiro de Mato Grosso, na perspectiva da gerar informações que contribuam para o planejamento e a gestão ambiental. Foi adotado o modelo de avaliação da fragilidade ambiental em que se utilizaram dos mapas de pedologia, dissecação do relevo, cobertura vegetal e uso da terra e precipitação. Os mapeamentos foram recortados pelas unidades de paisagem contidas na bacia hidrográfica do rio Jauru e associados em Sistemas de Informação Geográfica (SIG). As classes de fragilidade adotadas foram: fraca, média, forte e muito forte. O estado ambiental foi definido a partir da fragilidade ambiental e incompatibilidade no uso e ocupação da terra nas unidades de paisagem, assim o estado ambiental foi definido em: favorável, regular, crítico e muito crítico. A fragilidade forte ocorreu em $36,36 \%$ de toda da bacia, a fraca em $34,24 \%$, média em $27,09 \%$ e muito forte em $2,01 \%$. Predominou em $65,41 \%$ da bacia o estado ambiental crítico, o muito crítico em $20,88 \%$, favorável em $7,20 \%$ e regular em $6,51 \%$. Na bacia, conclui-se que a maioria das unidades de paisagem apresentaram fragilidade significativa devido às características físicas associadas ao manuseio impróprio pela agropecuária, contribuindo para a classificação do estado crítico da paisagem.
\end{abstract}

Palavras-chave: fragilidade ambiental; geotecnologias; conservação; planejamento ambiental.

\section{ASSESSMENT OF THE ENVIRONMENTAL STATUS OF THE LANDSCAPE UNITS OF A DRAINAGE BASIN IN THE BRAZILIAN STATE OF MATO GROSSO}

\begin{abstract}
Aim of this study is to assess the environmental status of the landscape units of a drainage basin in the Brazilian State of Mato Grosso, with a view to generating information that will contribute to environmental planning and management. It was adopted the environmental fragility assessment model, in which

\footnotetext{
${ }^{1}$ Universidade do Estado de Mato Grosso. miriamraquel18@gmail.com.

${ }^{2}$ Professora Adjunta do departamento de Geografia da Universidade do Estado de Mato Grosso. ssneves@unemat.br ${ }^{3}$ Universidade do Estado de Mato Grosso. cleberapbarros@gmail.com.

Estudos Geográficos, Rio Claro, 16(2): 31-45, jul./dez. 2018 (ISSN 1678-698X) http://www.periodicos.rc.biblioteca.unesp.br/index.php/estgeo
} 
they were used the maps of pedology, relief dissection, vegetation cover and land use and precipitation. The mappings have been clipped by landscape units contained in BHRJ and associates in SIG. The classes of fragility were Weak, average, adopted Strong and very strong. The State has been defined from the environmental fragility and environmental protection of the landscape units, so the State has been defined in Favour, Regular, critical and highly critical. The fragility "strong" occurred in the basin extension $36.36 \%$, weak in $34.24 \%$, the "average" in $27.09 \%$ and very strong in $2.01 \%$. Predominates in $65.41 \%$ of the basin the environmental status Critical, very critical in 20.88 percent, $7.20 \%$ favorable and the Regular "in $6.51 \%$. It is concluded that in the most of the landscape units are fragile due to erosion processes, interfering in the State of the landscape that is classified as critical.

Keywords: environmental fragility; geotechnology; conservation; environmental planning.

\section{INTRODUÇÃO}

O geossistema compreende um espaço caracterizado por certa homogeneidade de seus componentes, estruturas, fluxos e relações que, integrados, formam o ambiente físico, onde há exploração biológica (Troppmair, 2006). Nesse sentido, a paisagem é considerada uma face do Geossistema, o que é confirmado por Bertrand (2004) ao expor que a paisagem não é uma simples adição de elementos, mas o resultado da combinação dinâmica de elementos físicos, biológicos e antrópicos. Na perceptiva sistêmica, as unidades de paisagem permitem identificar áreas homogêneas na bacia hidrográfica, onde há combinação de diversos elementos naturais e sociais (Trombeta, 2016).

A análise por unidades de paisagem torna-se cada vez mais eficiente, uma vez que estas permitem a definição de potencialidades, fragilidades e problemas ambientais, contribuindo para tomadas de decisões pontuais (DIBIESO, 2013). Assim, o uso de indicadores constitui uma ferramenta hábil para a gestão ambiental, visto que sua aplicação contribui para a compreensão dos processos e interações que ocorrem na paisagem, ressaltando a necessidade de utilizar estas informações para tomadas de decisões voltadas à conservação e preservação (CRK et al., 2009).

Nesse contexto, utilizar indicadores é essencial para avaliar e monitorar os problemas ambientais vivenciados na bacia hidrografia do rio Jauru, que tem apontado altos níveis de degradação dos recursos naturais. A degradação pode ser considerada qualquer alteração adversa dos processos, funções, componentes ambientais ou uma alteração da qualidade ambiental (SÁNCHEZ, 2013). Rodrigues et al. (2008) afirmam que a bacia hidrográfica é considerada a unidade mais adequada de planejamento para uso e exploração dos recursos naturais, o que facilita o acompanhamento das alterações antrópicas. Dessa forma, o emprego de indicadores é importante para o planejamento ambiental, visto que envolve estratégias que buscam estabelecer o equilíbrio entre a natureza e a ação humana. Santos (2004) destaca que o planejamento ambiental surgiu impulsionado pelos conflitos gerados na exploração dos recursos naturais, o que desencadeou a necessidade de tornar compatível o uso da terra com a proteção do ambiente.

Analisar a fragilidade do ambiente é um instrumento importante do planejamento ambiental, pois sintetiza os elementos do meio físico e antrópico a

Estudos Geográficos, Rio Claro, 16(2): 31-45, jul./dez. $2018 \quad$ (ISSN 1678-698X) http://www.periodicos.rc.biblioteca.unesp.br/index.php/estgeo 
partir do grau de fragilidade, subsidiando as propostas para conservação e preservação ambiental (ROSS, 1992).

Para que o planejamento ambiental possa incorporar a análise das fragilidades do ambiente é necessário um estudo integrado de seus elementos, objetivando definir as áreas que requer maior proteção ou que apresentam mais restrições e, sobretudo, necessitam de ações diferenciadas para a gestão por parte dos órgãos públicos (TROMBETA et al, 2014, p. 161).

Os Sistemas de Informação Geográfica (SIG's) podem ser considerados ferramentas centrais do planejamento ambiental, uma vez que possibilitam a integração e análise de dados. De acordo com Assad e Sano (1998) os SIG's são considerados os instrumentos computacionais do geoprocessamento, permitem a coleta, armazenamento, recuperação, transformação e a apresentação de dados do mundo real para determinados objetivos específicos, que geralmente são subsídios às tomadas de decisões.

Sá (2010) aponta que, para o planejamento ambiental, o uso dos SIGs temse mostrado como uma ferramenta indispensável que possibilita criar de forma prática, rápida e menos onerosa bancos de dados e documentos cartográficos com as mais diversas informações que servem de base para tomadas de decisões quanto à paisagem.

Investigar a paisagem da região do rio Jauru é relevante devido a influência que ela exerce na Bacia do Alto Paraguai, onde se insere o bioma Pantanal e a planície alagável, pois o rio Jauru é um dos principais tributários do rio Paraguai, que recebe água de todos os demais cursos hídricos da Bacia do Alto Paraguai, propiciando o alagamento da planície pantaneira.

O uso e ocupação é responsável por diversas alterações na paisagem da bacia. As ações dos programas de incentivo a ocupação do Estado contribuíram para que a agricultura e pecuária fossem instadas, o que fez com que o solo da bacia hidrográfica do rio Jauru perdesse parte da fertilidade natural (SOUZA et al., 2009). Sabe-se que o uso inadequado da terra, pelo homem, pode causar problemas de degradação e atingir os setores econômicos, sociais e ambientais da área de estudo, que abrange 14 municípios da região sudoeste de planejamento do estado de Mato Grosso (MATO GROSSO, 2012), onde ocorrem três biomas: o Amazônia (58\%), o Cerrado (17\%) e o Pantanal (24\%), totalizando uma área de $11.697,72 \mathrm{Km}^{2}$, subdividida em nove sub-bacias. A área estudada é composta por planaltos e planícies drenados pelo rio Paraguai, com áreas de transição entre o Cerrado e a Floresta Amazônica (Figura 1).

Estudos Geográficos, Rio Claro, 16(2): 31-45, jul./dez. 2018 (ISSN 1678-698X) http://www.periodicos.rc.biblioteca.unesp.br/index.php/estgeo 


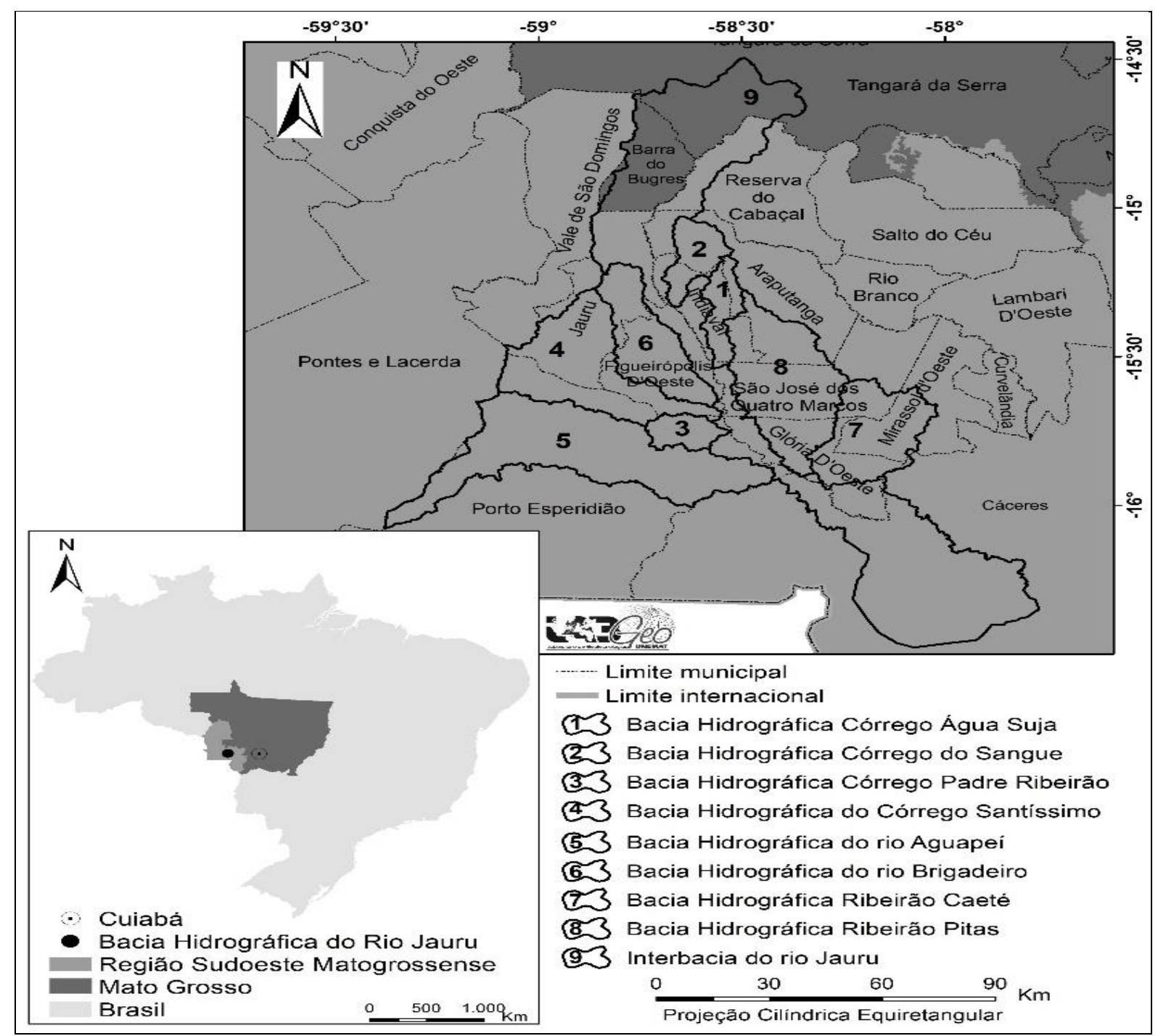

Figura 1 - Bacia hidrográfica do rio Jauru, contida na Região Sudoeste matogrossense - Brasil.

Fonte: Labgeo Unemat, 2017.

Nesse contexto, o objetivo deste trabalho foi avaliar o estado ambiental das unidades de paisagem da bacia hidrográfica do rio Jauru, situada no estado brasileiro de Mato Grosso, na perspectiva de gerar informações que contribuam para o planejamento e gestão ambiental.

Diante disso, as unidades de paisagem subsidiaram um diagnóstico mais detalhado da bacia hidrográfica, sendo que a análise das fragilidades consideram todos os atributos físicos de cada unidade mapeada, bem como a identificação de problemas do estado ambiental de cada uma delas, contribuindo para gerar informações mais detalhadas e tomadas de decisões específicas para cada unidade de paisagem.

\section{PROCEDIMENTOS METODOLÓGICOS}

Para definir e classificar as unidades de paisagem da área de estudo foram utilizados os compartimentos geomorfológicos, pois segundo Ross (1990, p. 12) "o entendimento do relevo passa [...] pela compreensão de uma coisa maior, que é a

Estudos Geográficos, Rio Claro, 16(2): 31-45, jul./dez. 2018 (ISSN 1678-698X) http://www.periodicos.rc.biblioteca.unesp.br/index.php/estgeo 
paisagem como um todo". Com base nos dados geomorfológicos, disponibilidados pela Secretaria de Estado de Planejamento e Coordenação Geral (SEPLAN-MT), foram utilizadas técnicas de sensoriamento remoto e análise espacial operacionalizadas no SIG.

Com o mapa preliminar das unidades foi realizado o trabalho de campo a partir do qual as informações geradas em laboratório foram contestadas com as informações do campo, e permitiram diferenciar e traçar os limites das unidades, a correção do mapa preliminar com informações complementares e a utilização de imagens de sensoriamento remoto.

Para avaliação da fragilidade ambiental foi adotado o modelo proposto por Ross (1994). Para tanto, os mapas de pedologia e dissecação do relevo foram levantados de fontes secundárias, disponibilizados pela Secretaria de Planejamento e Coordenação Geral de Mato Grosso no ano de 2001 na escala de 1: 500.000 e o mapa de precipitação em escala 1: 250.000 elaborado por Tarifa (2011).

O mapeamento da cobertura vegetal e uso da terra foi elaborado nesta pesquisa a partir da fotointerpretação de imagens orbitais do Landsat 8 , órbita/ponto 227/70, 228/71 e 228/71, referentes ao ano de 2016, com resolução de 30 metros, obtidas no Serviço Geológico Americano (USGS, 2015). As imagens foram processadas no Spring 5.3 (Câmara et al., 1996). Na segmentação, foram realizados testes com valores de limiares de similaridade e de área, sendo que os parâmetros definidos foram para similaridade e área de 50 e 100 pixel, respectivamente.

A partir da segmentação foram definidas as amostras necessárias à execução do treinamento e sua classificação, supervisionada adotando o método supervisionado (Classificador Bhattacharya), com limiar de aceitação de 99,9\% e, por último, foi realizado o mapeamento para as classes temáticas e a conversão matriz-vetor.

Com os dados supramencionados, seguiu-se os procedimentos apresentados na Figura 2, com base na proposta de Ross (1994) para levantamento da fragilidade ambiental $e$, por conseguinte, do estado ambiental segundo metodologia proposta por Trombeta (2015).

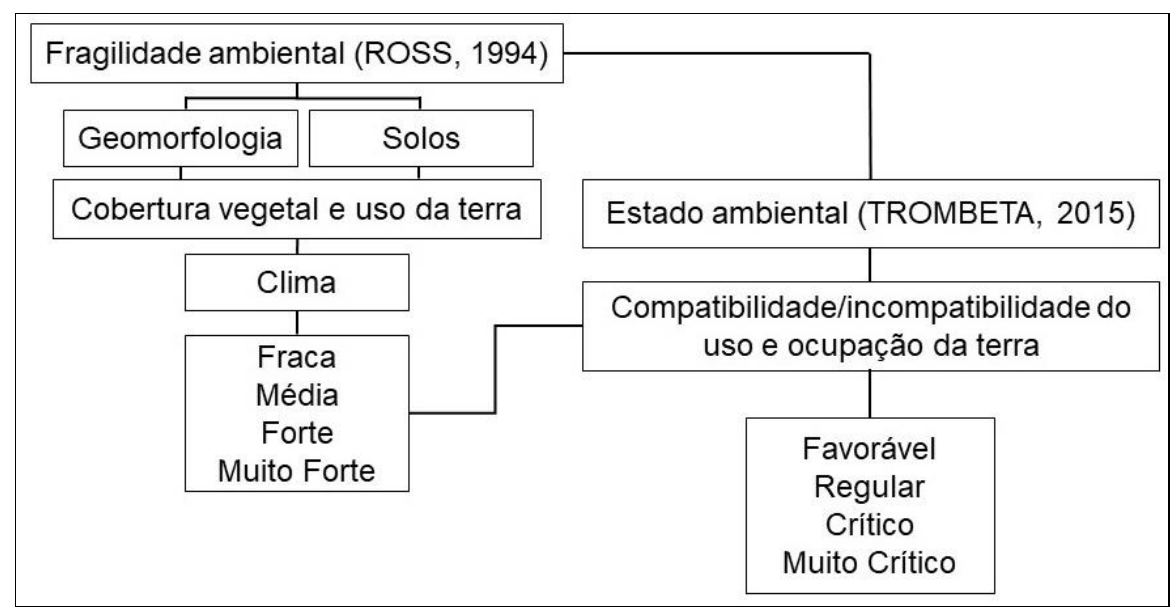

Figura 2 - Fluxograma metodológico.

Elaboração: Miranda, 2017.

Para a classificação da fragilidade, realizou-se a combinação dos dados com a ferramenta Intersect do ArcGIS 10.5 e, em seguida, todas as variáveis receberam um dígito, de um a cinco. A composição dos valores seguiu a proposta de Sporl e Ross (2004), sendo que o valor 'um' foi atribuído para condições de menor

Estudos Geográficos, Rio Claro, 16(2): 31-45, jul./dez. 2018 (ISSN 1678-698X) http://www.periodicos.rc.biblioteca.unesp.br/index.php/estgeo 
fragilidade, e o valor 'cinco' para aquelas de maior fragilidade, dissecação do relevo - muito fraca (1) a muito forte (5); Cobertura vegetal e uso da terra - grau de proteção muito alto (1) a muito baixo/nulo (5); Pedologia - fragilidade muito fraca (1) a muito forte (5); precipitação - muito baixa (1) a muito forte (5). Assim, a combinação entre os dígitos numéricos dos quatro planos de informação definiu as fragilidades como: fraca, média, forte e muito forte (Quadro 1).

\section{Quadro 1 - Composição das variáveis que definiram a fragilidade ambiental.}

\begin{tabular}{|c|c|c|}
\hline \multicolumn{2}{|c|}{ Variáveis } & Valores \\
\hline \multirow{4}{*}{$\begin{array}{c}\text { Dissecação do } \\
\text { Relevo }\end{array}$} & 250 e $750 \mathrm{~m}$ & 5 \\
\cline { 2 - 3 } & 750 e $1750 \mathrm{~m}$ & 4 \\
\cline { 2 - 3 } & 3750 e $1750 \mathrm{~m}$ & 2 \\
\hline \multirow{4}{*}{$\begin{array}{c}\text { Cobertura } \\
\text { vegetal e uso da } \\
\text { terra }\end{array}$} & Agricultura & 4 \\
\cline { 2 - 3 } & Água & 0 \\
\cline { 2 - 3 } & Pecuária & 3 \\
\cline { 2 - 3 } & Florestas baixas & 1 \\
\cline { 2 - 3 } & Floresta Aluvial & 1 \\
\cline { 2 - 3 } & Alreas de Mineração & 1 \\
\cline { 2 - 3 } & Influência urbana & 5 \\
\cline { 2 - 3 } & Savana & 5 \\
\cline { 2 - 3 } & Silvicultura & 3 \\
\cline { 2 - 3 } & Savana Florestada & 2 \\
\hline Precipitação & 1.800 mm & 4 \\
\hline \multirow{4}{*}{ Pedologia } & Argissolos & 3 \\
\hline & Latossolos & 2 \\
\cline { 2 - 3 } & Neossolos & 5 \\
\cline { 2 - 3 } & Organossolos & 2 \\
\cline { 2 - 3 } & Planossolos & 1 \\
\cline { 2 - 3 } & Plintossolos & 5 \\
\hline
\end{tabular}

O estado ambiental foi definido a partir da proposta de Trombeta (2015), com base nos problemas e fragilidades ambientais existentes, de acordo com as principais características de cada unidade da paisagem, considerando como principal elemento a compatibilidade/incompatibilidade da cobertura vegetal e uso da terra. Nesse sentido, o estado ambiental foi definido em: favorável, regular, crítico e muito crítico (Figura 3).

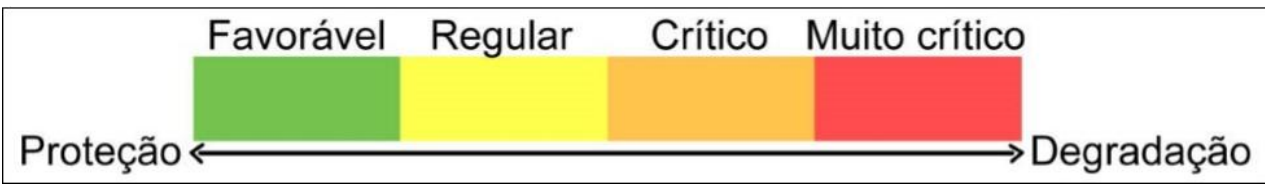

\section{Figura 3 - Classificação do estado ambiental.}

Elaboração: Trombeta (2015).

Foi realizada a validação dos resultados relativos ao estado ambiental, representados cartograficamente, por meio de dois trabalhos de campo no período seco e úmido, em locais das unidades de paisagem da área de estudo com intuito de sanar dúvidas derivadas da incompatibilidade entre os atributos físicos, cobertura vegetal e uso da terra.

Estudos Geográficos, Rio Claro, 16(2): 31-45, jul./dez. $2018 \quad$ (ISSN 1678-698X) http://www.periodicos.rc.biblioteca.unesp.br/index.php/estgeo 


\section{RESULTADO E DISCUSSÃO}

De acordo com as características físicas da bacia estudada e da ação antrópica foi possível constatar que ocorre o predomínio de forte fragilidade ambiental em $36,36 \%$, seguida da fraca com $34,24 \%$, sendo que $0,29 \%$ corresponde aos corpos d'água. (Tabela 1).

Tabela 1 - Fragilidade ambiental da bacia hidrográfica do rio Jauru/MT.

\begin{tabular}{lrc}
\hline \multicolumn{1}{c}{ Fragilidade Ambiental } & \multicolumn{1}{c}{$\mathbf{K m}^{\mathbf{2}}$} & $\%$ \\
\hline Fraca & $4.005,64$ & 34,24 \\
Média & $3.169,23$ & 27,09 \\
Forte & $4.253,45$ & 36,36 \\
Muito Forte & 235,09 & 2,01 \\
\hline \multicolumn{1}{c}{ Total } & $\mathbf{1 1 . 6 9 7 , 7 2}$ & $\mathbf{1 0 0}$ \\
\hline
\end{tabular}

Dentre as 50 unidades de paisagem definidas na bacia hidrográfica do rio Jauru, $14 \%$ apresentaram fragilidade fraca, $60 \%$ fragilidade média, $16 \%$ forte e $10 \%$ muito forte, distribuídas em toda área da bacia (Figura 4). Destacando que a maior parte da bacia tem fragilidade ao processo erosivo devido as características do revelo, solo e cobertura vegetal.

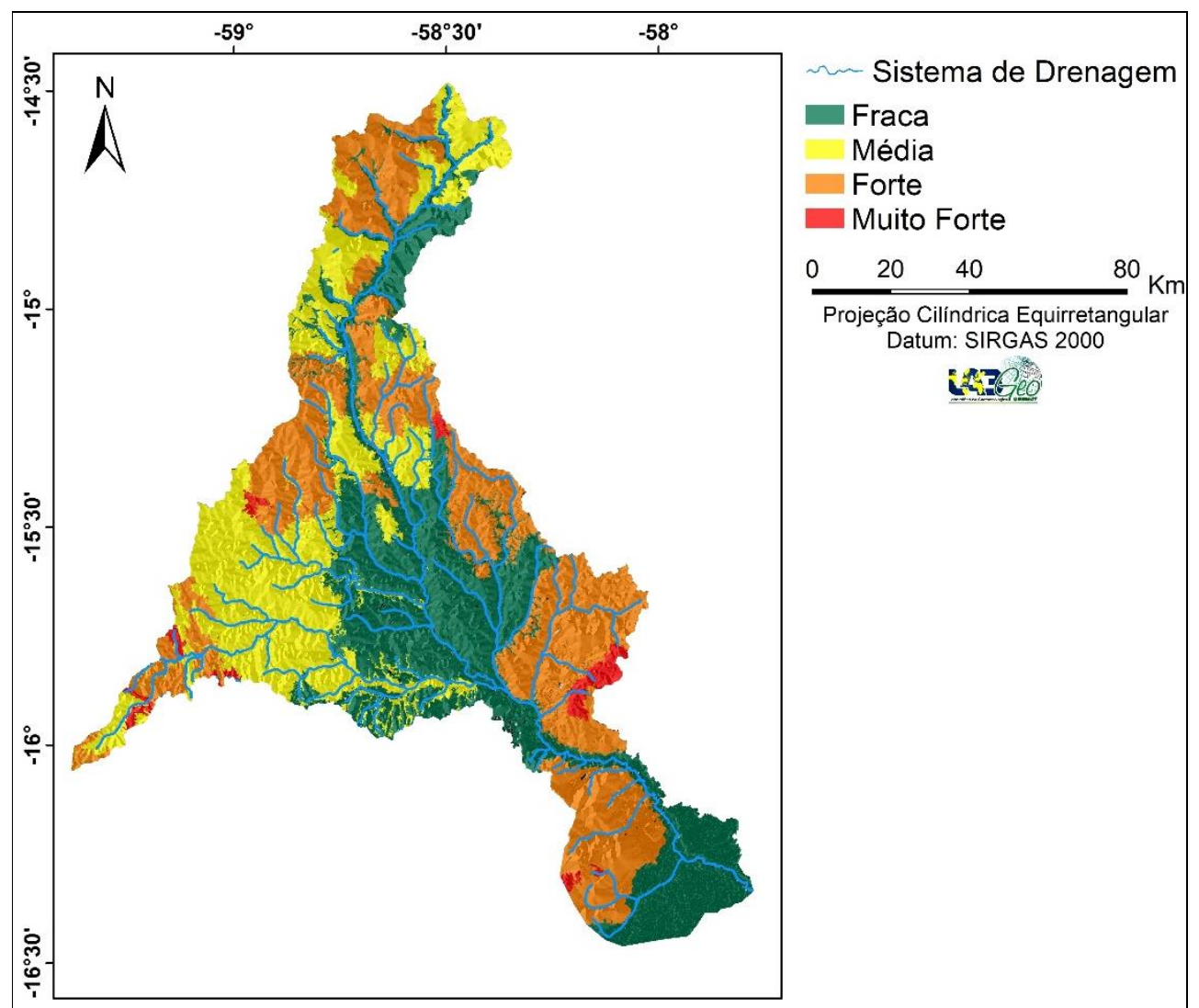

Figura 4 - Fragilidade ambiental das unidades de paisagem da Bacia Hidrográfica do Rio Jauru.

Fonte: Labgeo Unemat, 2017.

Estudos Geográficos, Rio Claro, 16(2): 31-45, jul./dez. 2018 (ISSN 1678-698X) http://www.periodicos.rc.biblioteca.unesp.br/index.php/estgeo 
A fragilidade fraca está presente nas unidades de paisagem: áreas de acumulação inundáveis do rio Jauru (1); formas aguçadas do rio Jauru com forte dissecação (11); formas convexas das nascentes do rio Jauru (13); formas convexas do ribeirão Caeté (16); formas convexas do rio Aguapeí (18); formas convexas do rio Jauru com média dissecação VII (28); formas convexas do rio Jauru com média dissecação VIII (29); formas tabulares do córrego Água Suja (32); formas tabulares do córrego do Sangue (34); formas tabulares do rio Aguapeí (36); formas tabulares do rio Jauru com forte dissecação (37); formas tabulares do rio Jauru com média dissecação (38); pediplano inumado do rio Jauru (40); planície fluvial do córrego Padre Ribeirão (42); planície fluvial do ribeirão Pitas (44); planície fluvial do rio Brigadeiro (46); planície fluvial do rio Jauru (47) e superfície pediplanada do rio Jauru (50). Segundo Duarte et al. (2014) a fragilidade fraca apresentada nessas áreas pode ser atribuída às menores declividades e ao predomínio de vegetação natural, o que auxilia na proteção do solo, embora as áreas de planícies fluviais apresentam dinâmica complexa.

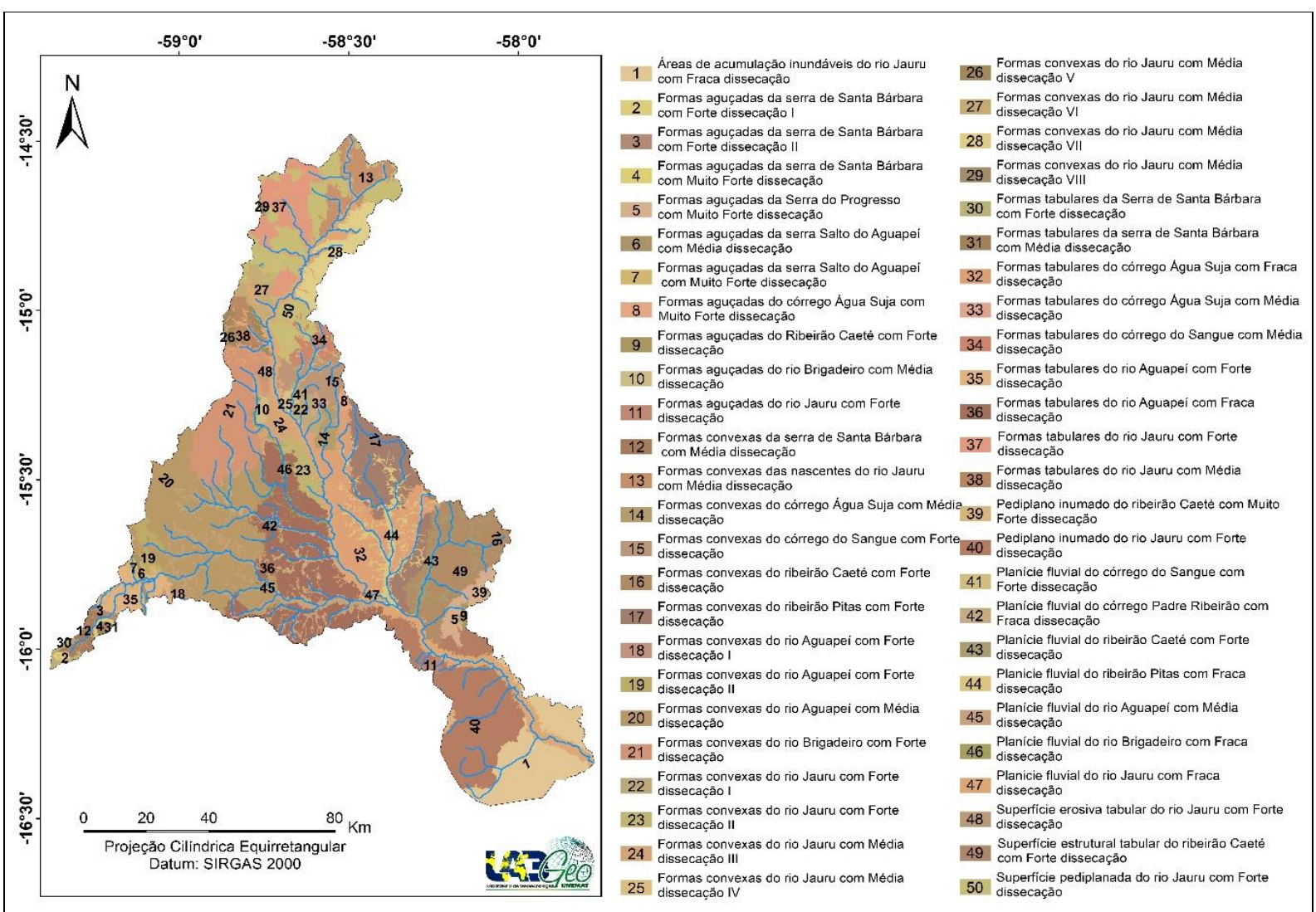

Figura 5 - Unidades de paisagem da BHRJ.

Fonte: Labgeo Unemat, 2017.

A fragilidade ambiental média ocorre em $27,09 \%$ da bacia hidrográfica do rio Jauru, distribuídas principalmente nas unidades: formas aguçadas da serra de Santa Barbará com forte dissecação, formas aguçadas da serra Salto do Aguapeí com média dissecação, formas convexas das nascentes do rio Jauru, formas convexas do rio Aguapeí e Planície fluvial do rio Aguapeí, demonstrando que nas unidades com fragilidade média os usos e os aspectos físicos estão associados de forma equilibrada, pois as áreas com vegetação remanescente podem diminuir a ação da erosão. O uso da terra modificado por intervenções de natureza humana possibilita

Estudos Geográficos, Rio Claro, 16(2): 31-45, jul./dez. $2018 \quad$ (ISSN 1678-698X) http://www.periodicos.rc.biblioteca.unesp.br/index.php/estgeo 
um grau médio ou baixo de proteção ao solo, que contribui para a classificação de média fragilidade ambiental (SANTOS et al., 2010).

A fragilidade forte ocorreu em 24 unidades de paisagem, são elas: formas aguçadas da serra de Santa Bárbara; formas aguçadas do Ribeirão Caeté; formas aguçadas da Serra do Progresso; formas aguçadas do rio Jauru; planície fluvial do ribeirão Caeté; formas convexas do córrego do Sangue; formas convexas do ribeirão Caeté; formas convexas do ribeirão Pitas; formas convexas do rio Aguapeí; formas convexas do rio Brigadeiro; formas convexas do rio Jauru, formas tabulares da Serra de Santa Barbará; formas tabulares do córrego Água Suja; formas tabulares do córrego do Sangue; formas tabulares do rio Aguapeí; formas tabulares do rio Jauru; formas tabulares do rio Jauru; pediplano inumado do rio Jauru; planície fluvial do córrego do Sangue; planície fluvial do ribeirão Caeté; planície fluvial do rio Aguapeí; planície fluvial do rio Jauru; superfície erosiva tabular do rio Jauru; superfície estrutural tabular do ribeirão Caeté; superfície pediplanada do rio Jauru (Figura 6). Nessas unidades a fragilidade forte é resultante da combinação das atividades agropecuárias e silviculturais, com os Neossolos que são impróprios para esses tipos de uso, visto que podem potencializar os processos de degradação ambiental. Sartori et al. (2005) alertam para a inserção de cultivos em tais solos, uma vez que se caracterizam por apresentar alta permeabilidade e suscetibilidade à erosão. Estudos desenvolvidos por Neves et al. (2011) estimando a perda de solo na bacia hidrográfica do rio Jauru apontaram a ocorrência de solos de alta erodibilidade, como Neossolos e Argissolos que recobrem $81 \%$ da área da bacia.

$\mathrm{Na}$ bacia, em 2,01\% de sua extensão, a fragilidade é muito forte e decorrente da atividade agropecuária em espaços identificado como áreas de média dissecação do relevo. Esse tipo de fragilidade se destacou nas unidades: formas aguçadas da Serra do Progresso; formas aguçadas da Serra de Santa Bárbara e formas aguçadas da serra do Aguapeí, cujas áreas apresentam relevo de forte dissecação, a exemplo das Serras Santa Barbará e Padre Inácio, localizadas a sudoeste e sudeste da bacia, respectivamente.

O estado ambiental da bacia hidrográfica do rio Jauru foi estabelecido pelos principais problemas ambientas encontrados: processos erosivos, assoreamento dos cursos d'água e desmatamento. Nesse sentido, a classe favorável foi definida em áreas com proteção vegetal em bom estado de conservação e preservação, sem problemas ambientais e com fragilidade ambiental entre fraca e média. Esse estado ambiental ocorreu em 7,2\%, ocupando as áreas a N e SO da bacia (Figura 6).

Estudos Geográficos, Rio Claro, 16(2): 31-45, jul./dez. $2018 \quad$ (ISSN 1678-698X) http://www.periodicos.rc.biblioteca.unesp.br/index.php/estgeo 


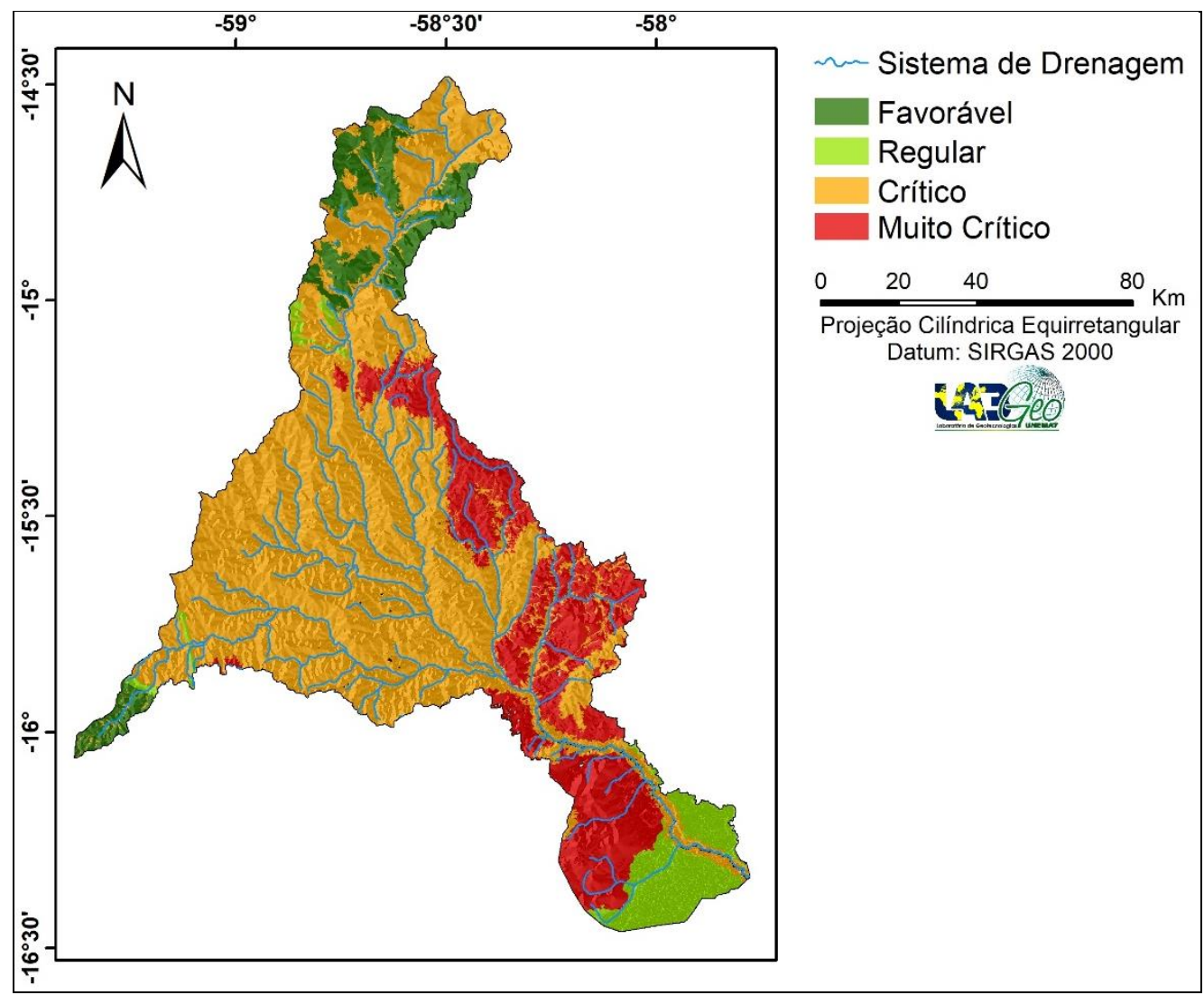

Figura 6 - Estado ambiental das unidades de paisagem da BHRJ.

Fonte: Labgeo Unemat, 2017.

$\mathrm{Na}$ bacia, as áreas com vegetação natural, dissecação média do relevo com predomínio de fragilidade forte foram consideradas estado regular $(6,51 \%)$ (Tabela 2). O estado crítico se dá pela escassa cobertura vegetal, usos antrópicos incompatíveis com o relevo, presença de erosões e desmatamento, apresentando fragilidade distribuída em toda a bacia hidrográfica do rio Jauru.

Tabela 2 - Estado ambiental da bacia hidrográfica do rio Jauru (MT)

\begin{tabular}{lrc}
\hline Estado Ambiental & \multicolumn{1}{c}{$\mathbf{K m}^{\mathbf{2}}$} & $\%$ \\
\hline Favorável & 842,56 & 7,20 \\
Regular & 761,15 & 6,51 \\
Crítico & $7.652,01$ & 65,41 \\
Muito Crítico & $2.442,00$ & 20,88 \\
\hline \multicolumn{1}{c}{ Total } & $\mathbf{1 1 . 6 9 7 , 7 2}$ & $\mathbf{1 0 0}$ \\
\hline
\end{tabular}

A classe muito crítica encontra-se na porção SE da bacia, em áreas de fragilidade forte e muito forte, marcada pela inexistência de cobertura vegetal, intensa ação da agropecuária em solos frágeis (Figura 7). Ocorrendo nas seguintes unidades de paisagem: Formas aguçadas do Córrego Água Suja (8); Formas convexas do Ribeirão Pitas (17); Formas convexas do rio Aguapeí (19); Superfície erosiva tabular do rio Jauru (48); Pediplano inumado do rio Jauru com forte dissecação (40); Pediplano inumado do Ribeirão Caeté com muito forte dissecação

Estudos Geográficos, Rio Claro, 16(2): 31-45, jul./dez. 2018 (ISSN 1678-698X) http://www.periodicos.rc.biblioteca.unesp.br/index.php/estgeo 
(39); Superfície estrutural tabular do Ribeirão Caeté (49); Formas convexas do Ribeirão Caeté (16); Formas convexas do Córrego do Sangue (15).

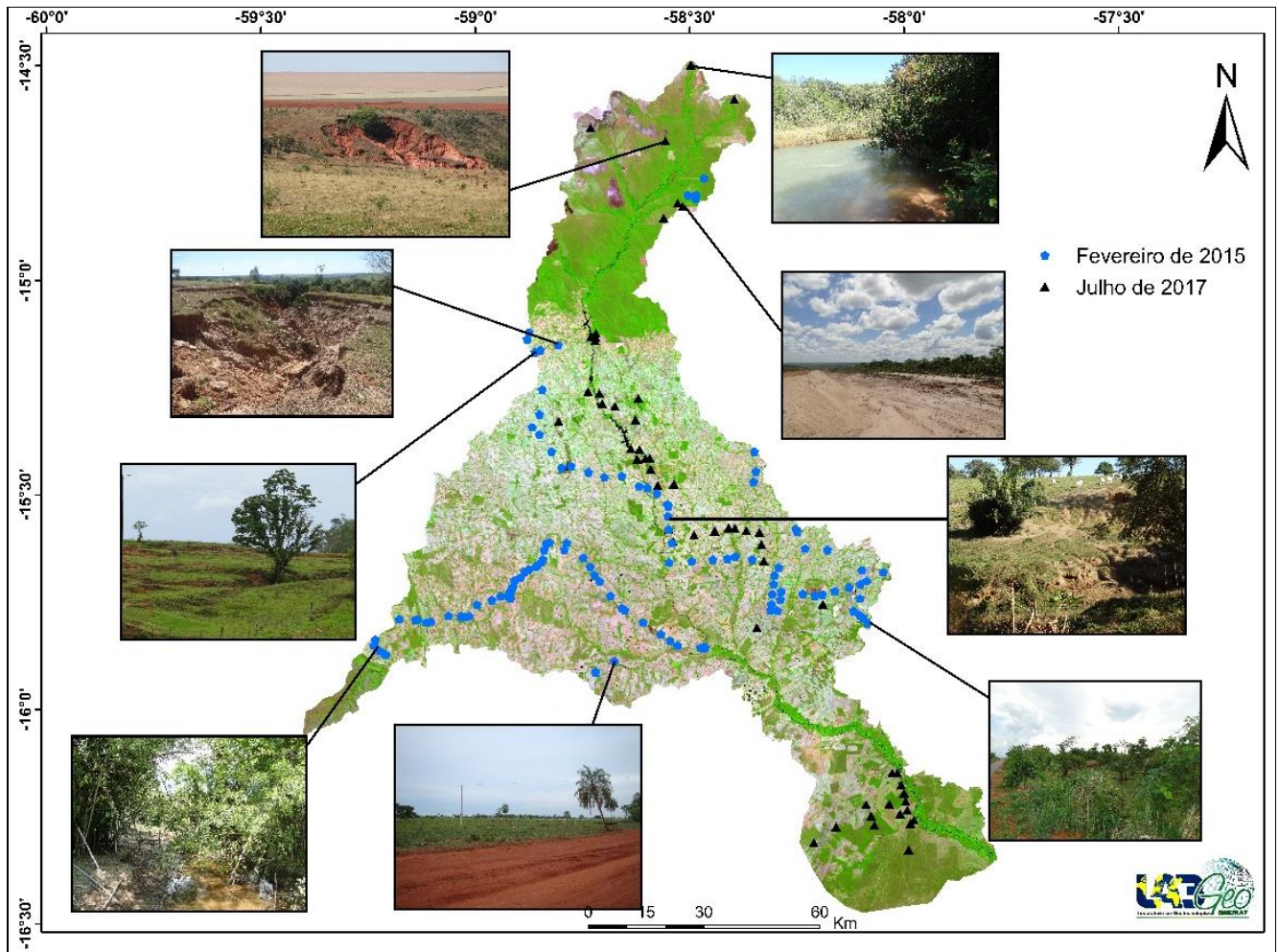

Figura 7 - Estado ambiental das unidades paisagem da BHRJ.

Fonte: Labgeo Unemat, 2017.

Na maior parte da bacia $(65,41 \%)$ o estado ambiental foi classificado como crítico, o qual incide em 28 de unidades de paisagem que apresentam relevo ondulado, fragilidade ambiental forte, onde a mata ciliar é substituída pela agropecuária. Soares et al. (2012) constataram que nas nascentes das sub-bacias da bacia do rio Jauru a pecuária é a principal responsável pela degradação da vegetação, causando prejuízos aos corpos d'água.

O estado muito crítico está presente em $20,88 \%$ da superfície da Bacia Hidrográfica do Rio Jauru, sendo que em dez unidades de paisagem o relevo é forte ondulado e em algumas unidades há poucas manchas de vegetação ou, até mesmo, nenhuma cobertura vegetal (Figura 8). Segundo Trombeta (2015) o estado muito crítico deve-se à incompatibilidade de uso da terra, considerando a ausência de proteção vegetal e mata ciliar ao longo dos cursos d'água, acelerando os processos erosivos. 


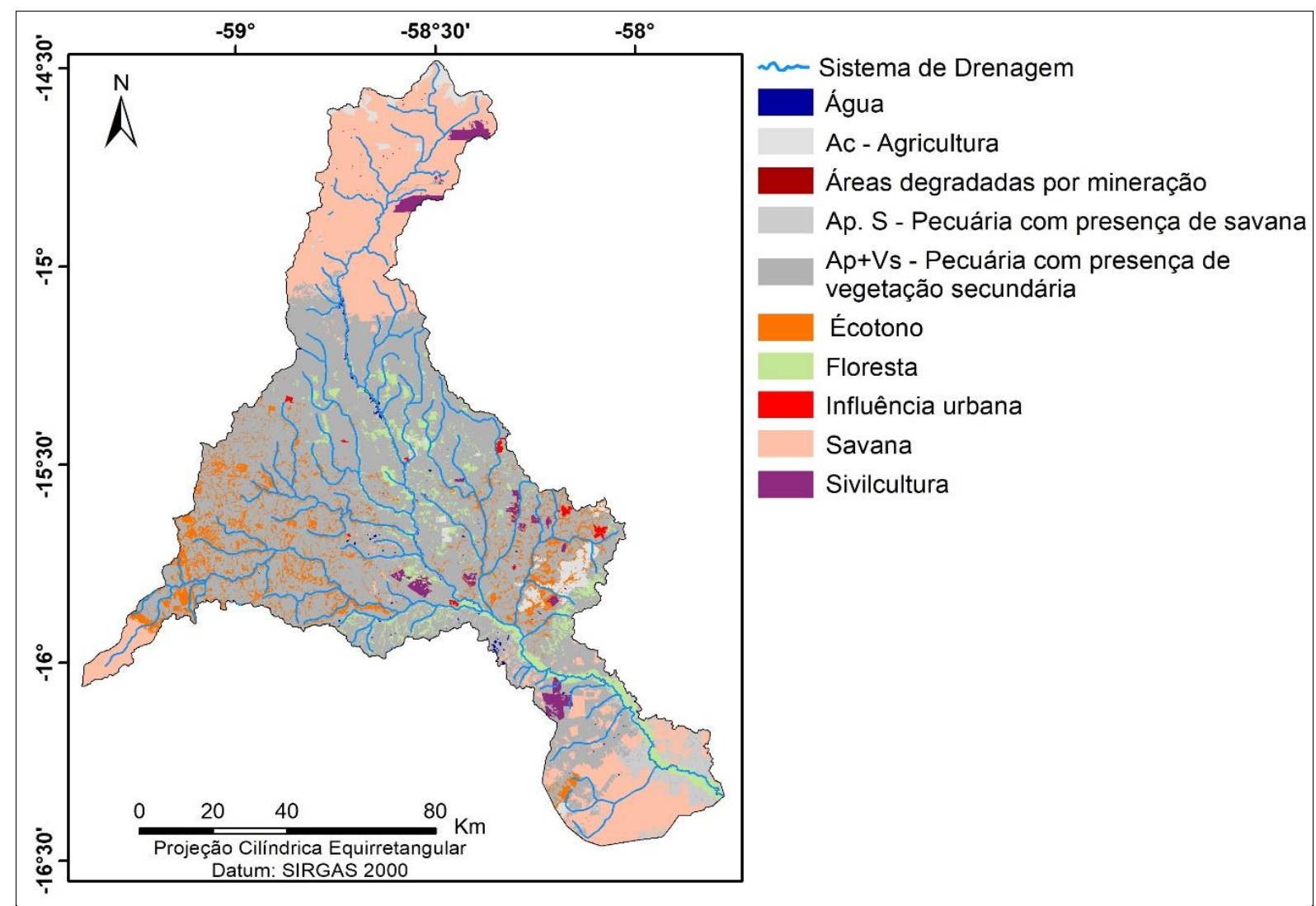

Figura 8 - Cobertura vegetal e uso da terra da Bacia Hidrográfica do Rio Jauru do ano de 2016.

Fonte: Labgeo Unemat, 2017.

Em $7,20 \%$ da extensão territorial da bacia o estado ambiental foi classificado como favorável, encontrado em oito unidades de paisagem, onde se registrou a presença de vegetação nativa e a fragilidade ambiental foi classificada como fraca. Essas unidades encontram-se na porção N e SO, Parque Estadual Serra de Santa Bárbara, demonstrando a importância dos Parques Estaduais na conservação e preservação ambiental.

A preservação restrita ao Parque Estadual, quando comparada ao mapa de Estado Ambiental, comprova que a preservação da área estudada é insuficiente, visto que a área do Parque ocupa cerca de $3 \%$ da área da bacia, com uma fragilidade muito forte. Cáceres (2017) aponta que programas como o pacto em defesa das cabeceiras do Pantanal têm recuperado nascentes dos rios Taquarussu e córrego do Ouro entre outras situadas no município de Jauru (MT), que contém parte da extensão da bacia hidrográfica do rio Jauru.

O estado ambiental regular correspondente a 6,51\% da área total (Tabela 2), no qual classificaram-se quatro unidades de paisagem, associadas ao manuseio do solo pela agropecuária e sua relação com a preservação e conservação do ambiente. Nessas unidades, em setores em que a fragilidade foi fraca, o uso da terra é voltado para pecuária, com intensa pressão por parte desse uso antrópico, especialmente nas unidades formas convexas do rio Jauru com média dissecação VI (25) e Formas aguçadas da serra Salto Aguapeí com média dissecação (6), onde apesar das condições físicas favoráveis, a intensificação do uso antrópico pode acarretar problemas ambientais, como erosão e redução das matas ciliares (Figura 8).

Estudos Geográficos, Rio Claro, 16(2): 31-45, jul./dez. $2018 \quad$ (ISSN 1678-698X) http://www.periodicos.rc.biblioteca.unesp.br/index.php/estgeo 
Através dos mapeamentos foi possível constatar que as áreas de planalto da bacia encontram-se em níveis críticos de conservação, necessitando de atenção especial dos órgãos ambientais quanto as novas supressões da vegetação. Tal situação, de acordo com Alho (2005) se reflete nas planícies inundáveis, as quais dependem quase que exclusivamente da proteção do planalto no entorno, onde se localizam as nascentes dos rios que favorecem a dinâmica do Pantanal (ALHO, 2005).

\section{CONCLUSÃO}

As unidades de paisagem da bacia hidrográfica do rio Jauru são consideradas, em sua maioria, desequilibradas, diante da alta fragilidade ambiental associadas ao manuseio incompatível das pastagens com as características físicas da bacia. O estado ambiental predominante nas unidades foi o crítico (56\%), seguido pelo muito crítico (18\%), evidenciando aumento de erosões.

O estado ambiental da bacia evidencia a necessidade de adotar medidas de proteção dos ambientes crítico e muito crítico, sobretudo nas unidades Planície fluvial do córrego do Sangue com forte dissecação, Planície fluvial do córrego Padre Ribeirão com fraca dissecação, Planície fluvial do rio Brigadeiro com fraca dissecação e Planície fluvial do rio Aguapeí com média dissecação, em que os recursos hídricos estão sendo impactados pela avanço da agricultura e pecuária, consequentemente, podem comprometer a dinâmica de inundação do Pantanal. Nesse sentido, esses dados podem ser utilizados no planejamento ambiental da região, subsidiando a tomada de decisão em relação ao manejo da terra, definindo ainda as unidades que necessitam de conservação ou preservação: Formas convexas das nascentes do rio Jauru e Planície Fluvial do rio Jauru.

\section{REFERÊNCIAS}

ALHO, C. J. R. The Pantanal. In: LAUCHLAND, H. F.; KEDDY, P. A. (Ed.). The World's Largest Wetlands: Ecology and Conservation. Cambridge: Cambridge University Press, 2005. p. 203-271.

ASSAD, E. D.; SANO, E. E. Sistemas de informações geográficas (Aplicações na Agricultura). Brasília: SPI/EMBRAPA-CPAC, 1998. 434p.

BERTRAND, G. Paisagem e geografia física global. Esboço metodológico. RA'E GA, v. 54, n.8, p.141-152, 2004.

BRASIL. Lei $n^{\circ} 12.651$, de 25 de maio de 2012. Dispõe sobre a proteção da vegetação nativa. Disponível em: http://www.planalto.gov.br/ccivil_03/_ato20112014/2012/lei/l12651.htm

BRASIL. Monitoramento do desmatamento nos biomas brasileiros por satélite. Acordo de cooperação técnica MMA/IBAMA. Centro de Sensoriamento Remoto CSR/IBAMA. 2008-2009. Brasília: MMA, 2011. Disponível em: http://www.mma.gov.br/estruturas/sbf_chm_rbbio/_arquivos/relatrio_tcnico_monitora mento_pantanal_2008_2009_72.pdf.

CÁCERES. Pacto em defesa das cabeceiras do pantanal já cercou 11 nascentes em Jauru. Jornal Oeste, $2017 . \quad$ Disponível em: Estudos Geográficos, Rio Claro, 16(2): 31-45, jul./dez. 2018 (ISSN 1678-698X) http://www.periodicos.rc.biblioteca.unesp.br/index.php/estgeo 
http://www.jornaloeste.com.br/noticias/exibir.asp?id=41679\&noticia=pacto_em_defes a_das_cabeceiras_do_pantanal_ja_cercou_11_nascentes_em_jauru

CÂMARA, G.; SOUZA, R. C. M.; FREITAS, U. M.; GARRIDO, J. SPRING: Integrating remote sensing and GIS by object-oriented data modeling. Computers \& Graphics, v. 20, n.3, p. 395-403, 1996.

CRK, T.; URIARTE, M.; CORSI, F.; FLYNN, D. Forest recovery in a tropical landscape: what is the relative importance of biophyical, socioeconomic, and landscape variables? Landscape Ecology, v. 24, n. 5, p. 629-642, 2009.

DUARTE, M. M.; VASCONCELLOS, B. N.; TERRA, L. G.; GIOTTO, E. Visualização da fragilidade ambiental do município de Fredrico Westphalen (RS) com a utilização de geotecnologias. Enciclopédia Biosfera, v. 10, n. 18, p. 1263-1275, 2014.

DIBIESO, E. P. Planejamento ambiental e gestão dos recursos hídricos: estudo aplicado à bacia hidrográfica do manancial do alto curso do Rio Santo Anastácio/SP. 2013. Tese de Doutorado em Geografia apresentada à Universidade Estadual Paulista (UEP - SP, Brasil).

FLORENZANO, T. G. Imagens de satélite para estudos ambientais. São Paulo: Oficina de Textos, 2002. 16p.

NEVES, S. M. A. S.; MOTINHO, M. C.; NEVES, R. J.; SOARES, E. R. C. Estimativa da perda de solo por erosão hídrica na bacia hidrográfica do rio Jauru/MT. Soc. \& Nat, v. 23, n. 34, p. 423-434, 2011.

RODRIGUES, F. M.; PISSARRA, T. C. T.; CAMPOS, S. Caracterização morfométrica da microbacia hidrográfica do córrego da Fazenda da Glória, município de Taguaritinga, SP. Irriga, v. 13, n. 3, p. 310-322, 2008.

ROSS, J. L. S. Análise empírica da fragilidade dos ambientes naturais e antropizados. Revista do Departamento de Geografia, v. 1, n. 8, p. 64-74, 1994.

ROSS, J. L. S. O registro cartográfico dos fatos geomorfológicos e a questão da taxonomia do relevo. Revista do Departamento de Geografia, v. 6, n. 1, p. 17-29, 1992.

SÁ, T. F. F.; COSTA FILHO, J. F.; FRANCISCO, P. R. M.; BRAGA JÚNIOR, J, M. Sistema de informações geográficas (SIG) para a gestão ambiental de bacias hidrográficas. In: Simpósio Brasileiro de Ciências Geodésicas e Tecnologias da Geoinformação, 3., Recife - PE, 2010. Anais...Recife: UFPE, 2010. p. 215- 228.

SÁNCHEZ, L. E. Avaliação de impacto ambiental: conceitos e métodos. $2^{\mathrm{a}} \mathrm{Ed}$. São Paulo; Oficina de Textos, 2013. 584p.

SANTOS, R. M.; NÓBREGA, M. T.; PAIVA, R. G.; SILVEIRA, H. Análise da fragilidade ambiental no município de Tamboara - PR: aplicação e estudo comparativo de duas metodologias. Geoambiente, v. 3, n. 14, p. 93-120, 2010.

SANTOS, R, F. Planejamento ambiental: teoria e prática. São Paulo: Oficina de Textos, 2004. 184p.

Estudos Geográficos, Rio Claro, 16(2): 31-45, jul./dez. $2018 \quad$ (ISSN 1678-698X) http://www.periodicos.rc.biblioteca.unesp.br/index.php/estgeo 
SARTORI, A.; LOMBARDI NETO, F.; GENOVEZ, A. M Classificação hidrológica de solos brasileiros para a estimativa da chuva excedente com o método do serviço de conservação do solo dos Estados Unidos parte 1: Classificação. Revista Brasileira de Recursos Hídricos, v. 10, n. 4, p. 05-18, 2005.

SOARES, J. C. O.; SILVA, L. N. P.; SODRÉ, I. C. S.; SOUZA, C. A., FERREIRA, E. Caracterização ambiental das nascentes da bacia hidrográfica do rio Jauru. In Souza, C. A., Sousa, J. B. \& Andrade, L. N. P. S (Eds.), Bacia hidrográfica do rio Jauru, Mato Grosso - Dinâmica espacial e impactos associados. São Carlos: RiMa, 2012. p. 163-186.

SOUZA, C. A.; SOUSA, J. B.; SILVA, J. P.; ROEDER, A. P.; TORTORELLI, H. S.; VALERIANA, J.; SILVA, L. N. P.; ARAUJO, R. M. Análise demográfica, estrutura fundiária, produção agropecuária e relação das características do meio físico com uso do solo na bacia hidrográfica do rio Jauru-MT. In: SOUZA, C. A.; SOUSA, J. B. (Org.) Estudos geoambientais na bacia hidrográfica do Alto Paraguai - MT. Cáceres/MT: Ed. Unemat, 2009. p. 10-30.

SPÖRL, C.; ROSS, J. L. S. Análise comparativa da fragilidade ambiental com aplicação de três modelos. Espaço e Tempo, v. 1, n. 15, p. 39-49, 2004.

TROPPMAIR, H.; GALINA, M. H. Geossistemas. Mercator - Revista de Geografia da UFC, v. 5, n.10, p. 79-89, 2006.

TROMBETA, L. R.; LEAL, A. C. Planejamento ambiental e geoecologia das paisagens: contribuições para a bacia hidrográfica do córrego Guaiçarinha, município de Álvares Machado, São Paulo, Brasil. Revista Formação (ONLINE), v. 3, n. 3, p. 187-216, 2016.

TROMBETA, L. R. Planejamento ambiental da bacia hidrográfica do Córrego Guaiçarinha, município de Álvares Machado, São Paulo, Brasil. 2015. Dissertação de Mestrado em Geografia apresentada à Universidade Estadual Paulista (UEP - SP, Brasil).

USGS. Serviço de Levantamento Geológico Americano. Disponível em: $<$ http://landsat.usgs.gov>. Acessado em: 10 jan. 2015.

Artigo submetido em: 06/12/2017

Aceito para publicação em: 19/09/2018

Publicado em: 14/12/2018

Estudos Geográficos, Rio Claro, 16(2): 31-45, jul./dez. $2018 \quad$ (ISSN 1678-698X) http://www.periodicos.rc.biblioteca.unesp.br/index.php/estgeo 